\title{
QUALIDADE QUÍMICA DO SOLO COM DIFERENTES NÍVEIS DE DEGRADAÇÃO EM ÁREA DE PRESERVAÇÃO PERMANENTE
}

\author{
Denise Andréia Szymczak ${ }^{1,}$ Flávia Gizele Konig Brun², Eleandro José Brun³, \\ Suzana Ferreira da Rosa ${ }^{4}$, Eduardo Kneipp Londero ${ }^{5}$ \\ ${ }^{1}$ Engenheira Florestal, mestranda do Programa de Pós-Graduação em Engenharia Florestal da Universidade Federal de \\ Santa Maria, Departamento de Ciências Florestais, Santa Maria, Rio Grande do Sul, E-mail: \\ deniseszymczak@gmail.com . \\ ${ }^{1}$ Engenheira Florestal, Professora Doutora da Universidade Tecnológica Federal do Paraná - campus Dois Vizinhos, \\ Departamento de Ciências Florestais, Dois Vizinhos, Paraná, E-mail: flaviagizele@gmail.com . \\ ${ }^{1}$ Engenheiro Florestal, Professor Doutor da Universidade Tecnológica Federal do Paraná Campus Dois Vizinhos, \\ Departamento de Ciências Florestais, Dois Vizinhos, Paraná, E-mail: eleandroutfpr@gmail.com . \\ ${ }^{1}$ Engenheira Florestal, Doutoranda do Programa de Pós-Graduação em Engenharia Florestal da Universidade Federal \\ de Santa Maria, Departamento de Ciências Florestais, Santa Maria, Rio Grande do Sul, E-mail: \\ suzanafdr@yahoo.com.br. \\ ${ }^{1}$ Engenheiro Florestal, Mestre em Engenharia Florestal. E-mail: eklondero@gmail.com .
}

http://dx.doi.org/10.5902/223613086377

\section{RESUMO}

O objetivo deste trabalho foi verificar possíveis efeitos das contaminações do solo decorrente da poluição pela urbanização e uso desordenado nas margens do curso da Sanga lagoão do Ouro através de variáveis químicas do solo analisadas com ferramentas de estatística multivariada. Foram estabelecidos cinco pontos de amostragem no percurso urbano da Sanga que possuem diferentes usos e manejos. Houve alterações nas características químicas do solo de acordo com o manejo imposto. Por similaridade, observou-se a formação de três padrões de características químicas: fertilidade do solo (1), acidez (2), e pela quantidade de $\mathrm{MO}, \mathrm{N}$ e K (3) presente no solo. Quatro fatores (representados por F1, F2, F3 e F4), explicaram 88,34\% da variação total dos dados, sendo que o fator F1 representa a maior explicação da variância, com $48 \%$ e agrupa características relacionadas à fertilidade do solo. Na matriz de correlação das variáveis $38,6 \%$ das correlações são significativas indicando uma boa adequação para Análise Fatorial.

Palavras-chave: Urbanização; qualidade de vida; poluição do solo.

\section{ABSTRACT \\ CHEMICAL QUALITY OF SOIL WITH DIFFERENT LEVELS OF DEGRADATION IN THE ENVIRONMENTAL PERMANENT PRESERVATION AREAS}

The objective of this study was to investigate possible effects of soil contamination from pollution by urbanization and inordinate use of the course on the shores of the Sanga Lagoão of Ouro through soil chemical variables analyzed with multivariate statistical tools. We established five sampling points in the path of urban Sanga that have different uses and management. Alterations in the characteristics of soil in accordance with the management imposed. Similarity was observed the formation of three patterns chemical characteristics: soil fertility (1), acidity (2), and the amount of MO, N and $\mathrm{K}(3)$ in the soil. Four factors (represented by F1, F2, F3 and F4), explained $88.34 \%$ of the total variation of the data, and the factor F1 is the greatest explanation of the 
variance, with $48 \%$ and group characteristics related to soil fertility. In the correlation matrix of variables $38.6 \%$ of the correlations are significant indicating a good fit for factor analysis.

Keywords: Urbanization; life quality; soil pollution

\section{INTRODUÇÃO}

O crescimento populacional Brasileiro é acelerado e a demanda por espaços urbanos vem aumentando, segundo dados do Instituto Brasileiro de Geografia e Estatística - IBGE (2010), o Brasil tem $84 \%$ da população vivendo em área urbana.

A expansão desordenada dos centros urbanos afeta negativamente os recursos naturais, dentre os quais, o solo é um dos elementos da paisagem que sofre intensa pressão, sendo necessário seu estudo para se efetuar o planejamento urbano de acordo com o seu potencial de uso. "Solos urbanos" são os solos que se encontram no meio urbano e que apresentam um conjunto de possíveis modificações nas suas propriedades devido às atividades antrópicas exercidas nesse meio. As principais funções desempenhadas pelos solos no meio urbano são: suporte e fonte de material para obras civis, agricultura urbana, implantação e manutenção de áreas verdes, meio para descarte de resíduos e armazenamento e filtragem de águas pluviais (Pedron et al., 2004).

A ocupação humana irregular dos solos nos centros urbanos resulta, muitas vezes, na sua contaminação por materiais poluentes ou patogênicos ao homem e animais domésticos. Segundo Brasil (1981), a poluição do solo significa a presença de níveis de algum elemento ou substância que pode afetar componentes bióticos do ecossistema, comprometendo sua funcionalidade e sustentabilidade. Além do mais, esta urbanização informal oferece às pessoas, precárias condições de vida, pois força a realização de aterro, remoção de vegetação, especialmente das Áreas de Preservação Permanente, lançamento de águas servidas, abertura de vielas e disposição de lixo a céu aberto (Menegat et al., 1998).

Estes solos possuem influência na saúde humana pelo contato direto e frequente com as pessoas (MADRID et al., 2002). Em vários contextos, tem sido relatada, a poluição dos solos por metais pesados e substâncias tóxicas orgânicas e inorgânicas, sendo essencial sua detecção para evitar problemas relacionados à saúde, bem como degradações ambientais (ACCIOLY \& SIQUEIRA, 2000).

A influência antrópica nos solos urbanos pode provocar muitas alterações morfológicas, sendo comum encontrarmos camadas distintas e artificiais resultante da introdução de diferentes materiais, na tentativa de reconstituição do solo removido (Pedron e Dalmolin, 2002; Pedron, 2005). Além destas, há também alterações nas suas características físicas, químicas causadas pela presença, em quantidades variadas, de materiais não pedogenéticos como restos de tijolos, concretos, madeiras, plásticos, borrachas, vidros, pedaços de ferrose restos de pavimentos entre outros. A presença de esgoto, fezes deanimais ou lixo transforma o solo em fonte potencial de transmissão de várias doenças (Glasson e Dalmolin, 2005).

Com isso, o objetivo do estudo visou formar grupos ou padrões de degradação ambiental do solo com vistas à similaridade apresentada pelos atributos químicos analisados e assim gerar informações para a comunidade e gestores locais a fim de facilitar iniciativas de recuperação do ambiente. 


\section{MATERIAL E MÉTODOS}

\section{Descrição da área de estudo}

A área do estudo localiza-se no Bairro Camobi, município de Santa Maria-RS. É margeado pelo Rio Vacacaí-Mirim que integra a Bacia do Rio Jacuí, tendo como um de seus tributários, a Sanga Lagoão do Ouro, objeto do estudo. A nascente localiza-se no Residencial Novo Horizonte, percorrendo o Núcleo Habitacional Fernando Ferrari, Vila Santos Dumont, Vila Santa Tereza, Vila Assunção e o Campus da Universidade Federal de Santa Maria. Segundo a hierarquia fluvial proposta por Christofoletti (1979) é um rio de 3 a ordem e apresenta 11,5 km de extensão. A área analisada no estudo corresponde à extensão de $3 \mathrm{~km}$, correspondente a área urbana do tributário, sujeita ao acúmulo de lixo, lançamento de esgoto nas águas, entre outras intervenções antrópicas. Permeando esta área urbana, existem ainda pequenas áreas ocupadas por lavouras e pastagens, que também apresentam sinais típicos de degradação.

O Bairro Camobi teve início de sua ocupação a partir da Vila estação Colônia que se formou de um antigo povoado de imigrantes italianos que recebia o nome de Estação Colônia, conforme Fontoura (1993), a ocupação inicial se deu no entorno da Estação Ferroviária do Distrito de Estação Colônia, que com a instalação da Universidade Federal e Base Aérea de Santa Maria, e com a instalação de indústrias ao longo da RS-509 (Avenida Prefeito Evandro Behr) iniciou-se o processo de evolução urbana e de articulação entre a Cidade de Santa Maria e a área do Bairro Camobi.

Atualmente pelo elevado grau de urbanização e densidade demográfica do Bairro Camobi que conta com uma população de 13.311 habitantes, que correspondem a 5,8\% do total da população urbana do município, as áreas vagas dentro dos Parques residenciais são praticamente inexistentes, o que leva às classes sociais mais altas ocuparem espaços dentro das Vilas, gerando conflitos de paisagem e segregações sociais dentro das próprias Vilas.

Os solos no qual se situam a sanga pertencem às Unidades de Mapeamento São Pedro e Santa Maria, sendo classificados respectivamente como: Argissolo Vermelho distrófico arênico e Argissolo Bruno-Acinzentado alítico úmbrico. Sendo o Argissolo Vermelho distrófico arênico caracterizado como de textura média, ocorre sob relevo ondulado e substrato arenítico, são solos, geralmente, profundos e bem drenados, com uma sequência de horizontes $A-E-B t-C$, contendo argilas de baixa CTC, e apresenta alta suscetibilidade a erosão e degradação.

O clima da região em estudo caracteriza-se como subtropical úmido, do tipo Cfa, caracterizado pela temperatura média anual compreendida entre 17,9 e $19,2^{\circ} \mathrm{C}$, com as chuvas bem distribuídas ao longo do ano e uma precipitação média anual em torno de $1770 \mathrm{~mm}$ (Moreno, 1961).

\section{METODOLOGIA}

Dentro do percurso urbano da Sanga foram estabelecidos 5 pontos de amostragem com diferentes usos e manejo. 0 ponto 1 , na nascente da Sangano Residencial Novo Horizonte, margem direita (P1D) e margem esquerda (P1E); o ponto 2 no início do Núcleo Habitacional Fernando Ferrari (COHAB Fernando Ferrari), margem direita (P2D) e margem esquerda (P2E);O ponto 3 localiza-se na porção final do Núcleo Habitacional Fernando Ferrari (COHAB Fernando Ferrari), margem direita (P3D) e margem esquerda (P3E); o ponto 4 está nas imediações da Avenida Rodolfo Behr, na altura da Vila Santa Tereza, margem direita (P4D) e margem esquerda 
(P4E) e o último ponto de coleta fica na Avenida Roraima, entrada do Campus da Universidade Federal de Santa Maria, margem direita (P5D) e margem esquerda (P5E). Tais pontos foram georeferenciados com auxílio de GPS Topográfico Promark (Tabela 1), com esses dados foi confeccionado, em SPRING 4.1, um mapa de localização (Figura 1).

Tabela 1. Coordenadas geográficas dos pontos amostrados ao longo da sanga Lagoão do Ouro.

\begin{tabular}{lccc}
\hline Ponto & Latitude & Longitude & Altitude $(\mathrm{m})$ \\
\hline Ponto 01 & $29^{\circ} 42^{\prime} 30,78594^{\prime \prime} \mathrm{S}$ & $53^{\circ} 43^{\prime} 51,23262^{\prime \prime} \mathrm{W}$ & 118,001 \\
Ponto 02 & $29^{\circ} 42^{\prime} 33,93738^{\prime \prime} \mathrm{S}$ & $53^{\circ} 43^{\prime} 30,56644^{\prime \prime} \mathrm{W}$ & 113,236 \\
Ponto 03 & $29^{\circ} 42^{\prime} 34,38657^{\prime \prime} \mathrm{S}$ & $53^{\circ} 43^{\prime} 21,11683^{\prime \prime} \mathrm{W}$ & 117,308 \\
Ponto 04 & $29^{\circ} 42^{\prime} 40,15696^{\prime \prime} \mathrm{S}$ & $53^{\circ} 43^{\prime} 06,68161^{\prime \prime} \mathrm{W}$ & 107,675 \\
Ponto 05 & $29^{\circ} 43^{\prime} 08,16189^{\prime \prime} \mathrm{S}$ & $53^{\circ} 42^{\prime} 59,71863^{\prime \prime} \mathrm{W}$ & 119,461 \\
\hline
\end{tabular}

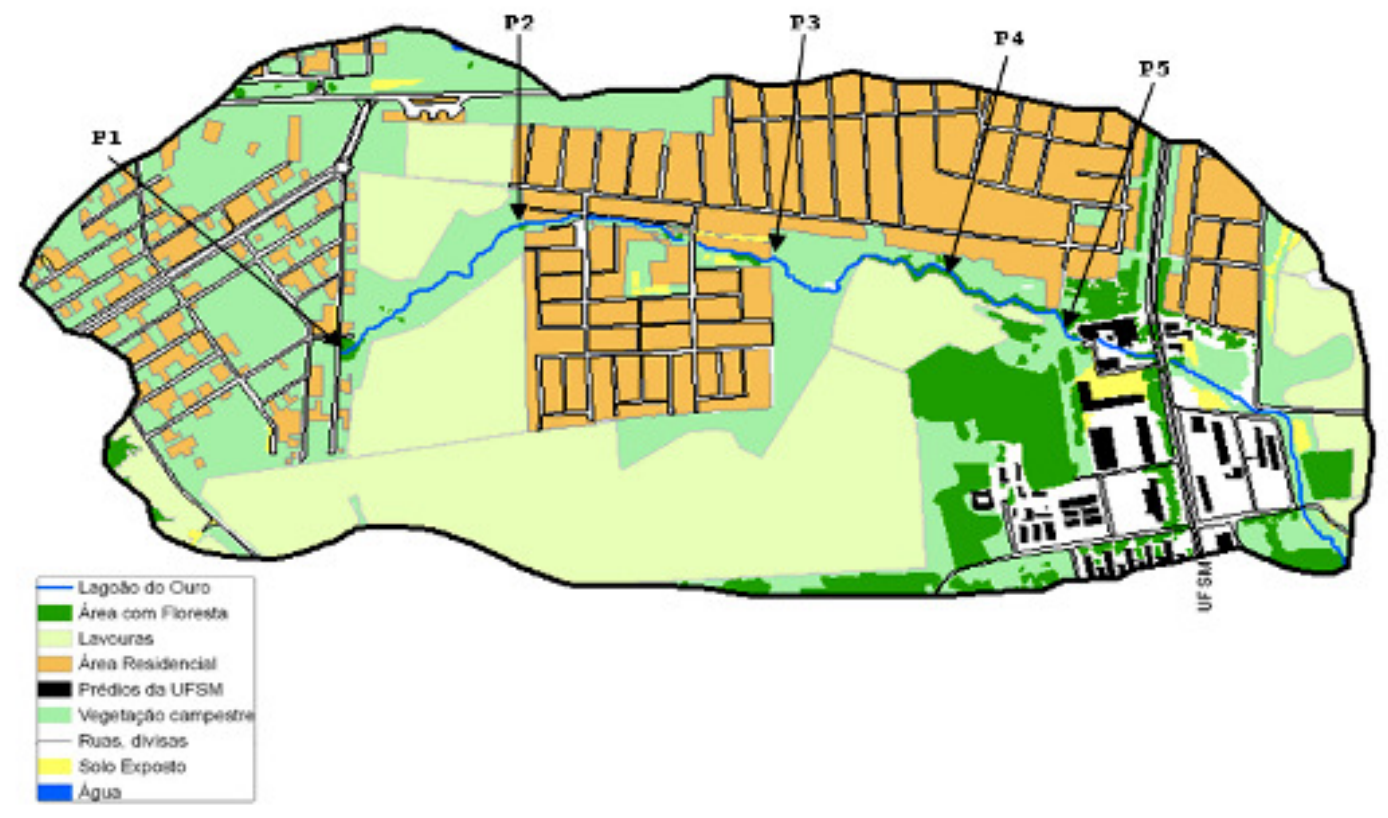

Figura 1. Pontos de monitoramento das características do solo na Área de Preservação Permanente da Sanga Lagoão do Ouro.

Em cada um destes pontos, de forma perpendicular ao leito da sanga, foi coletado amostra de solo na distância de 20 metros do leito normal da sanga na profundidade de $0-20 \mathrm{~cm}$.

Após a coleta do material, foram determinadas as seguintes propriedades químicas do solo: $\mathrm{pH}$, Matéria Orgânica (M.O), Nitrogênio (N), Alumínio (Al), H+Al, CTC ef., Argila, Fósforo (P), Potássio (K), Cálcio (Ca), Magnésio (Mg), Saturação de Al ( $\mathrm{m}$ \%), Saturação de Bases (V), Manganês (Mn), Zinco (Zn), Cobre (Cu), Enxofre (S), Boro (B) e Ferro (Fe), conforme Tedesco et al. (1995).

A análise das informações geradas a partir da caracterização química do solo foi realizada utilizando-se técnicas estatísticas de Análise Multivariada como: Análise de Agrupamentos e 
Análise Fatorial. A primeira avalia o grau de similaridade entre os diferentes pontos ao longo do curso de água com relação às propriedades químicas do solo. Utilizou-se a distância Euclidiana como medida de similaridade entre os pontos de coleta. $\mathrm{O}$ agrupamento dos pontos foi realizado através do Método de Ward, um procedimento que resulta em agrupamentos de tamanhos aproximadamente iguais devido a sua minimização de variação interna. A análise fatorial foi realizada empregando o método de componentes principais, cujos fatores associam as variáveis resultantes a cada variável original, e a carga fatorial expressa o quanto cada variável está associada a cada fator, os autovalores refletem a importância de cada um dos fatores envolvidos, podendo revelar agrupamentos ou tendências que poderiam ser difíceis de visualizar nas variáveis originais.

\section{RESULTADOS E DISCUSSÃO}

\section{Análise de agrupamentos}

Como produto da análise de Cluster foi obtido um dendograma (Figura 2), considerando a distância de combinação 5, observa-se que a distribuição dos pontos de coleta do solo formam 3 grupos ou padrões.Um grupo é composto pelos pontos P3D, P5D, P4D e P5E. Outro é formado pelo ponto P2D e P2E e o P4E. O terceiro engloba o P1D e P1E e também o P3E.

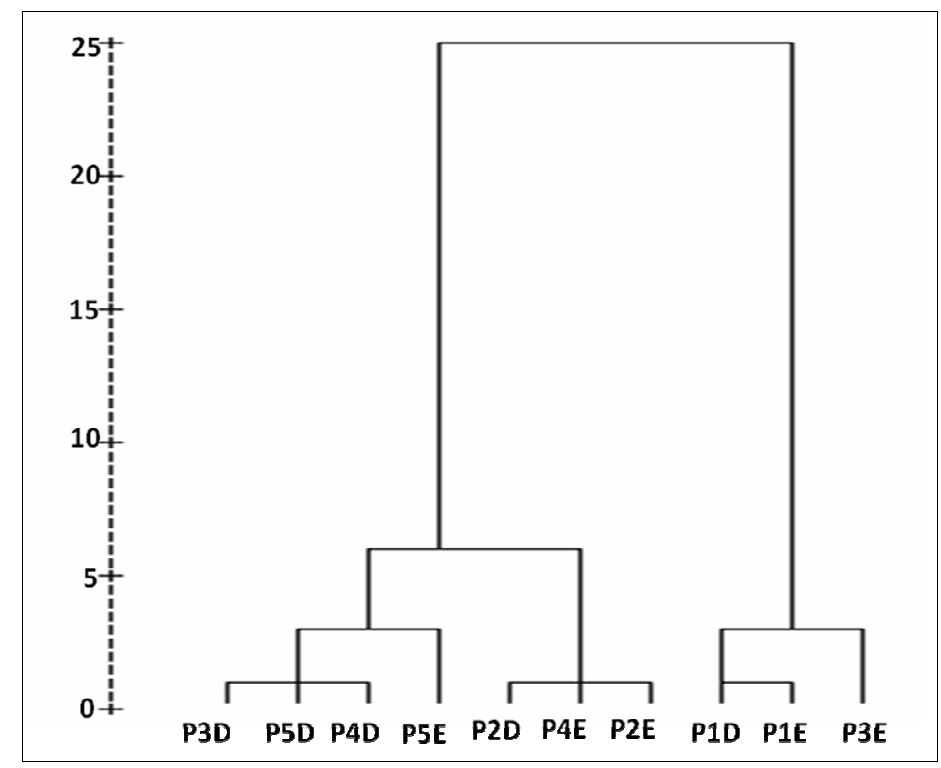

Figura 2. Dendograma da Análise de Agrupamentos.

A causa principal da similaridade entre os locais de coleta do solo está ligada ao uso do solo em cada ponto. Um dos grupos formados é composto pelo P1D e E, que corresponde à nascente da Sanga e em ambos as margens existe vegetação característica de manancial, despejo de lixo e esgoto das casas que ficam à jusante, enquanto o P3E corresponde à área de pastejo de gado e 
também recebe toda a carga de poluente vinda da COHAB Fernando Ferrari que contribui para a contaminação do solo e alteração de suas propriedades químicas (Tabela 2).

O P4E, P2D e P2E refletem condições de áreas de cultivo agrícola e de pastejo de animais em que, meses antes da coleta de solo o P2D e P2E sofreram queima da vegetação rasteira contribuindo para aumentar os valores de M.O. e N, através da mineralização da matéria orgânica por ocasião da queima dos resíduos orgânicos. $\mathrm{O} \mathrm{Al}^{+3} \mathrm{e} \mathrm{H+Al}$ apresentaram valores elevados o que contribuiu para a maior acidez desse grupo, fator relacionado ao uso da área. Nesses pontos também se verifica a grande concentração de $\mathrm{K}^{+}$presente no solo, oriunda da fertilização aplicada nas culturas como soja e milho. Também se observa a menor disponibilidade de $\mathrm{P}$, com relação às áreas que compõem os outros dois grupos (Tabela 2).

Algumas práticas de preparo do solo ou de simples limpeza podem colaborar para o aumento da acidez. Em uma revisão de literatura realizada por Jacques (2003) a respeito dos efeitos das queimadas sobre o solo e a vegetação, o autor comprovou que a queima resulta em maiores teores de saturação de Alumínio, e maior acidez potencial do solo, bem como menores teores de Magnésio na camada superficial do solo.

O terceiro grupo engloba basicamente a margem direita da Sanga, sendo composta por: P5D e P5E, P3D e P4D. Os pontos 3 e 4 apresentaram os menores teores de M.O no solo, uma vez que são locais onde ocorre pastejo contínuo do gado (P3D) e lavoura com sistema de manejo convencional (P4D). O pastejo contínuo e o cultivo do solo com preparo intensivo contribuem para a degradação da matéria orgânica do solo, devido a mobilização do solo e a incorporação dos resí- 
Monografias Ambientais

\begin{tabular}{|c|c|c|c|c|c|c|c|c|c|c|c|c|c|c|c|c|c|c|}
\hline \multirow{2}{*}{ Pontos } & $\mathrm{pH}_{\mathrm{H} 2 \mathrm{O}}$ & M.O & $\mathbf{N}$ & $\mathrm{Al}^{+3}$ & \multirow[t]{2}{*}{$\mathrm{H}+\mathrm{Al}$} & \multirow[t]{2}{*}{$\mathrm{CTC}_{\mathrm{ef}}$} & \multicolumn{2}{|r|}{$\mathrm{K}^{+}$} & $\mathrm{Ca}^{+2}$ & $\mathrm{Mg}^{+2}$ & $m$ & $\mathbf{V}$ & $M n$ & $\mathrm{Zn}$ & $\mathrm{Cu}$ & $S$ & B & $\mathrm{Fe}$ \\
\hline & & \multicolumn{2}{|c|}{$\%$} & $\mathrm{cmol}_{\mathrm{c}} \mathrm{dm}^{-3}$ & & & \multicolumn{2}{|c|}{$\mathrm{mg} \mathrm{dm}^{-3}$} & \multicolumn{2}{|c|}{$\mathrm{cmol}_{\mathrm{c}} \mathrm{dm}^{-3}$} & \multicolumn{2}{|c|}{$\%$} & \multicolumn{6}{|c|}{$\mathrm{mg} \mathrm{dm}^{-3}$} \\
\hline P1D & 4,89 & 2,14 & 1,1 & 0,86 & 7,49 & 7,71 & 7,19 & 49,28 & 4,6 & 2,11 & 11,91 & 47,65 & 27,96 & 5,21 & 1,53 & 5 & 0,44 & 442,06 \\
\hline P1E & 4,74 & 1,53 & 0,8 & 0,99 & 9,23 & 5,05 & 2,09 & 38,84 & 2,85 & 1,11 & 19,83 & 32,53 & 11,75 & 1,5 & 1,35 & 6,9 & 0,6 & 406,13 \\
\hline P3E & 4,81 & 1,45 & 0,75 & 0,73 & 5,24 & 6,59 & 10,88 & 40,34 & 4,76 & 0,99 & 11,45 & 52,7 & 29,79 & 1,26 & 1,46 & 12,2 & 0,6 & 372 \\
\hline P3D & 4,55 & 1,59 & 0,81 & 1,58 & 10,63 & 6,29 & 3,46 & 51,29 & 3,25 & 1,34 & 24,98 & 31,71 & 24,44 & 1,08 & 1,04 & 13,06 & 0,58 & 296,7 \\
\hline P4D & 4,5 & 1,41 & 0,75 & 1,75 & 12,09 & 6,93 & 10,7 & 45,03 & 3,81 & 1,25 & 25,24 & 31,06 & 7,34 & 0,78 & 1,11 & 14,93 & 0,53 & 280,99 \\
\hline P5D & 4,64 & 1,74 & 0,86 & 1,78 & 10,38 & 5,86 & 8,63 & 63,15 & 2,6 & 1,29 & 33,35 & 27,61 & 29,94 & 2,14 & 1,03 & 8,41 & 0,58 & 285,51 \\
\hline P5E & 5,14 & 1,04 & 0,55 & 0,68 & 6,2 & 13,28 & 3,04 & 49,63 & 9,39 & 3,09 & 5,3 & 67,53 & 55,9 & 4,79 & 5,51 & 8,73 & 0,39 & 284,93 \\
\hline P2D & 4,49 & 2,43 & 1,21 & 2,08 & 12,4 & 9,15 & 5,11 & 85,63 & 4,84 & 2,03 & 24,09 & 36,61 & 28,2 & 3,35 & 2,1 & 14,83 & 0,59 & 324,31 \\
\hline P2E & 4,5 & 2,35 & 1,18 & 1,98 & 13,6 & 6,5 & 3,4 & 67,65 & 3,2 & 1,11 & 31,45 & 25,71 & 18,41 & 2,24 & 1,44 & 18,86 & 0,75 & 354,95 \\
\hline P4E & 4,98 & 1,58 & 0,79 & 1,81 & 9,71 & 9,1 & 3,7 & 63,28 & 4,65 & 2,38 & 21,74 & 44,13 & 7,35 & 1,29 & 1,9 & 14,84 & 0,53 & 324,93 \\
\hline
\end{tabular}

TABELA 2: Características químicas do solo divididas por grupos de Pontos formados na Análise de Agrupamentos. 
duos orgânicos que promove a rápida decomposição da matéria orgânica do solo. O P5E localizase nas imediações da Gráfica Universitária, local de gramado, sem acúmulo de resíduos vegetais.

\section{Análise fatorial}

Visando o entendimento sobre as relações entre as propriedades químicas do solo sob diferentes usos e o grau de degradação e ainda, demonstrar a contribuição de cada variável química na avaliação da qualidade do solo fez-se uso da análise fatorial (Tabela 3). Dos 18 possíveis fatores (atributos químicos do solo) observa-se que ocorreu a formação de quatro fatores (representados por F1, F2, F3 e F4), os quais explicaram 88,34\% da variação total dos dados, sendo que o fator F1 representa a maior explicação da variância, com $48 \%$.

Tabela 3. Autovalores e percentual da variância explicada e acumulada referente às características químicas avaliadas.

\begin{tabular}{cccc}
\hline Fator & Autovalor & Variância (\%) & Variância Acumulada (\%) \\
\hline F1 & 9,18 & 48,33 & 48,33 \\
F2 & 4,16 & 21,92 & 70,25 \\
F3 & 2,37 & 12,47 & 82,72 \\
F4 & 1,07 & 5,62 & 88,34 \\
\hline
\end{tabular}

A Tabela 4 apresenta as cargas fatoriais, a partir das quais foi escolhido para interpretação de cada fator o conjunto de variáveis originais que apresentam pesos maiores que 0,500 e menores que $-0,500$. Observa-se que a maioria das vaiáveis analisadas possuem cargas fatoriais significativas sobre apenas um fator. Dessa forma, os resultados revelam associação entre as seguintes características químicas do solo: $\mathrm{pH}, \mathrm{CTC}_{\mathrm{ef}}, \mathrm{Ca}, \mathrm{Mg}$, valor de $\mathrm{m}, \mathrm{V}, \mathrm{Mn}, \mathrm{Zn}, \mathrm{Cu}$ e $\mathrm{B}$, com valores superiores a 0,500 no F1que explica $48,34 \%$ da variância total dos dados. O F2 explica $21,92 \%$ da variância total e apresenta uma maior contribuição do pH, Al, H+Al, K, m, V, S e Fe. No F3, M.O., N e K tiveram maior associação e explica $12,47 \%$ da variância dos dados. O F4 é representado apenas pelo $\mathrm{P}$ e explica apenas $5,623 \%$ de toda a variância. Foi observada ambiguidade nos F1 e F2 para o $\mathrm{pH}, \mathrm{m}$, V, e K nos F2 e F3.

No Fator F1 agruparam-se as características relacionadas à fertilidade e os micronutrientes, os quais também se correlacionam entre si (Tabela 5). Resultado semelhante ao observado no norte do Mississipe por Brejda et al. (2000), no qual o Ca e Mg trocáveis se correlacionaram fortemente entre si e com a CTC e teor de argila do solo.

No Fator 2 (F2) ficou claro o agrupamento de características referentes à acidez do solo $\left(\mathrm{pH}, \mathrm{Al}^{+3}, \mathrm{H}+\mathrm{Al}\right.$ e $\left.\mathrm{m}\right)$, enquanto no Fator 3 (F3) estão associados à M.O., N e K. Estas variáveis são mais facilmente influenciadas pelas cargas poluidoras advindas das áreas de urbanização que rodeiam a sanga. A menor contribuição dos micronutrientes nestes fatores se relaciona ao fato de serem elementos de baixa mobilidade no solo e por ligarem mais fortemente as partículas do solo(CQFS, 2004). Em contrapartida, se observa que apesar dos micronutrientes representarem pouca contribuição na formação dos fatores F2 e F3, eles se correlacionaram com a maioria das propriedades químicas que compõem também o fator F1. 
O quarto fator (F4) foi definido somente pelo Fósforo, pois o P não se correlacionou com outra variável (Tabela 5) e apresentou alta variabilidade dos teores entre os pontos de coleta avaliados (2,09 a 10,88 $\mathrm{mg} \mathrm{dm}^{-3}$ ). Segundo Machado (2012) o fósforo está presente no solo em sua maior parte (67 a 71\%) na forma orgânica, estando atrelado à mineralização e liberação deste nutriente pelo componente orgânico do solo (M.O) e dessa forma também é afetado pela degradação ambiental a qual se apresenta no local do estudo.

Tabela 4. Cargas fatoriais da matriz rotacionada para as características químicas do solo com diferentes graus de degradação ambiental.

\begin{tabular}{ccccc}
\hline \multirow{2}{*}{ Var. } & \multicolumn{4}{c}{ Componentes Rotacionados (Carga fatorial) } \\
\cline { 2 - 5 } $\mathrm{pH}$ & $\mathrm{F} 1$ & $\mathrm{~F} 2$ & $\mathrm{~F} 3$ & $\mathrm{~F} 4$ \\
$\mathrm{M} . \mathrm{O}$ & $\mathrm{n}, 574$ & $-0,582$ & $\mathrm{~ns}$ & $\mathrm{~ns}$ \\
$\mathrm{~N}$ & $\mathrm{~ns}$ & $\mathrm{Ns}$ & 0,950 & $\mathrm{~ns}$ \\
$\mathrm{Al}$ & $\mathrm{ns}$ & $\mathrm{Ns}$ & 0,952 & $\mathrm{~ns}$ \\
$\mathrm{H}+\mathrm{Al}$ & $\mathrm{ns}$ & 0,890 & $\mathrm{~ns}$ & $\mathrm{~ns}$ \\
$\mathrm{CTC}$ ef & $\mathrm{ns}$ & 0,792 & $\mathrm{~ns}$ & $\mathrm{~ns}$ \\
$\mathrm{Argila}$ & 0,967 & $\mathrm{Ns}$ & $\mathrm{ns}$ & $\mathrm{ns}$ \\
$\mathrm{P}$ & 0,738 & $\mathrm{Ns}$ & $\mathrm{ns}$ & $\mathrm{ns}$ \\
$\mathrm{K}$ & $\mathrm{ns}$ & $\mathrm{Ns}$ & $\mathrm{ns}$ & $\mathrm{ns}$ \\
$\mathrm{Ca}$ & $\mathrm{ns}$ & 0,652 & 0,640 & $\mathrm{~ns}$ \\
$\mathrm{Mg}$ & 0,915 & $\mathrm{Ns}$ & $\mathrm{ns}$ & $\mathrm{ns}$ \\
$\mathrm{M}$ & 0,916 & $\mathrm{Ns}$ & $\mathrm{ns}$ & $\mathrm{ns}$ \\
$\mathrm{V}$ & $-0,558$ & 0,716 & $\mathrm{~ns}$ & $\mathrm{~ns}$ \\
$\mathrm{Mn}$ & 0,748 & $-0,516$ & $\mathrm{~ns}$ & $\mathrm{~ns}$ \\
$\mathrm{Zn}$ & 0,757 & $\mathrm{Ns}$ & $\mathrm{ns}$ & $\mathrm{ns}$ \\
$\mathrm{Cu}$ & 0,718 & $\mathrm{Ns}$ & $\mathrm{ns}$ & $\mathrm{ns}$ \\
$\mathrm{S}$ & 0,900 & $\mathrm{Ns}$ & $\mathrm{ns}$ & $\mathrm{ns}$ \\
$\mathrm{B}$ & $\mathrm{ns}$ & 0,773 & $\mathrm{~ns}$ & $\mathrm{~ns}$ \\
$\mathrm{Fe}$ & $-0,684$ & $\mathrm{Ns}$ & $\mathrm{ns}$ & $\mathrm{ns}$ \\
\hline
\end{tabular}

Foram consideradas significativas as cargas fatoriais maiores que 0,500 e menores que -0,500;ns = não significativo.

Os solos agrícolas brasileiros, na maioria, apresentam média a alta acidez, com pH $\mathrm{H}_{2} \mathrm{O}$ menor 5,5 (Bissani et al., 2006), o que se confirmou nos valores de pH nas amostras de solo em estudo. Os solos ácidos geralmente apresentam alumínio e manganês em nível tóxicos, além de deficiências de cálcio, magnésio e fósforo (Veloso et al., 1992). Os teores de argila se enquadram na classe 4 segundo CQFS (2004). Baseado no mesmo autor os teores de $P$ são considerados de

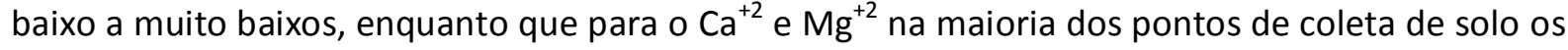
teores são considerados altos (incremento de lixo urbano).

Na matriz de correlação das variáveis (Tabela 5 ) verifica-se que $38,6 \%$ das correlações são significativas ao nível de $p<0,01$, indicando uma boa adequação para análise fatorial. Variáveis como o Fe e o P não tiveram nenhuma correlação com as demais variáveis analisadas. Em contrapartida o $\mathrm{pH}$ teve correlação com a maioria das outras variáveis, o que já se esperava, tendo em vista que as relações no solo são, em sua maioria, dependentes do pH, pois é o controlador das 
ligações químicas. Laurent et al. (2010) também observou uma elevada correlação do pH do solo com os micronutrientes do solo em área de mineração.

$\mathrm{O} \mathrm{Cu}$ relaciona-se diretamente com o pH do solo, havendo redução do $\mathrm{Cu}$ disponível em solos com pH mais alto, pois o $\mathrm{Cu}$ forma complexo de esfera-interna com os óxidos de ferro e alumínio, sendo trocado por íons $\mathrm{H}^{+}$com a elevação desses íons na solução do solo, a qual corresponde à redução do pH em água (Bissani et al., 2004).

$\mathrm{O} \mathrm{pH}$ teve correlação negativa com M.O., $\mathrm{N}, \mathrm{Al}^{+3}, \mathrm{H}+\mathrm{Al}, \mathrm{m}$ e B. Maiores teores de matéria orgânica promovem a acidificação do solo, pois a ionização do $\mathrm{H}$ dos grupos carboxílicos, fenólicos e álcoois existentes na matéria orgânica contribuem para redução do pH. Além disso, a mineralização dos compostos orgânicos, ao sofrerem oxidação, podem liberar prótons para a solução do solo, promovendo a acidificação. A correlação negativa entre $\circ \mathrm{pH}$ e $\circ \mathrm{Al}^{+3}$ está de acordo com Souza et al. (2007), o qual afirma a existência de uma relação inversa entre o $\mathrm{Al}^{+3}$ (acidez trocável) com o $\mathrm{pH}$ do solo. $\mathrm{O} \mathrm{B}$ é adsorvido ao solo por troca de ligantes com $\mathrm{OH}^{-}$, com isso, havendo um baixo valor de $\mathrm{pH}$, há baixa concentração de íons oxidrilas no solo e com isso há baixa disponibilidade de $\mathrm{B}$ no solo.

Tabela 5. Correlação das características químicas avaliadas a 0,00-0,20 m de um solo com diferentes usos e manejos.

\begin{tabular}{|c|c|c|c|c|c|c|c|c|c|c|c|c|c|c|c|c|c|c|c|}
\hline Var. & $\mathrm{pH}$ & M.O & $\mathrm{N}$ & $\mathrm{Al}^{+3}$ & $\mathrm{H}+\mathrm{Al}$ & $\mathrm{CTC}_{\mathrm{ef}}$ & Argila & $\mathrm{P}$ & $\mathrm{K}^{+}$ & $\mathrm{Ca}^{+2}$ & $\mathrm{Mg}^{+2}$ & $\mathrm{~m}$ & V & $\mathrm{Mn}$ & $\mathrm{Zn}$ & $\mathrm{Cu}$ & $\mathrm{S}$ & B & $\mathrm{Fe}$ \\
\hline $\mathrm{pH}$ & 1,0 & & & & & & & & & & & & & & & & & & \\
\hline M.O & $-0,5$ & 1,0 & & & & & & & & & & & & & & & & & \\
\hline $\mathrm{N}$ & $-0,5$ & 0,9 & 1,0 & & & & & & & & & & & & & & & & \\
\hline $\mathrm{Al}^{+3}$ & $-0,7$ & 0,5 & 0,5 & 1,0 & & & & & & & & & & & & & & & \\
\hline $\mathrm{H}+\mathrm{Al}$ & $-0,8$ & 0,6 & 0,6 & 0,9 & 1,0 & & & & & & & & & & & & & & \\
\hline $\mathrm{CTC}_{\mathrm{ef}}$ & 0,6 & $-0,3$ & $-0,3$ & $-0,2$ & $-0,3$ & 1,0 & & & & & & & & & & & & & \\
\hline Argila & 0,1 & 0,3 & 0,2 & 0,2 & 0,2 & 0,7 & 1,0 & & & & & & & & & & & & \\
\hline $\mathrm{P}$ & $-0,2$ & $-0,1$ & $-0,1$ & $-0,1$ & $-0,2$ & $-0,3$ & $-0,4$ & 1,0 & & & & & & & & & & & \\
\hline $\mathrm{K}^{+}$ & $-0,3$ & 0,7 & 0,7 & 0,7 & 0,6 & 0,2 & 0,7 & $-0,2$ & 1,0 & & & & & & & & & & \\
\hline $\mathrm{Ca}^{+2}$ & 0,7 & $-0,4$ & $-0,4$ & $-0,5$ & $-0,5$ & 0,9 & 0,5 & $-0,2$ & $-0,1$ & 1,0 & & & & & & & & & \\
\hline $\mathrm{Mg}^{+2}$ & 0,7 & $-0,2$ & $-0,2$ & $-0,2$ & $-0,3$ & 0,9 & 0,7 & $-0,4$ & 0,2 & 0,8 & 1,0 & & & & & & & & \\
\hline $\mathrm{m}$ & $-0,8$ & 0,5 & 0,5 & 0,9 & 0,9 & $-0,6$ & $-0,1$ & 0,1 & 0,5 & $-0,8$ & $-0,5$ & 1,0 & & & & & & & \\
\hline V & 0,9 & $-0,5$ & $-0,5$ & $-0,7$ & $-0,8$ & 0,8 & 0,2 & $-0,1$ & $-0,3$ & 0,9 & 0,7 & $-0,9$ & 1,0 & & & & & & \\
\hline $\mathrm{Mn}$ & 0,5 & $-0,2$ & $-0,2$ & $-0,5$ & $-0,5$ & 0,6 & 0,4 & $-0,1$ & 0,1 & 0,7 & 0,5 & $-0,5$ & 0,7 & 1,0 & & & & & \\
\hline $\mathrm{Zn}$ & 0,5 & 0,2 & 0,3 & $-0,4$ & $-0,3$ & 0,6 & 0,6 & $-0,2$ & 0,2 & 0,6 & 0,7 & $-0,5$ & 0,5 & 0,7 & 1,0 & & & & \\
\hline $\mathrm{Cu}$ & 0,7 & $-0,4$ & $-0,4$ & $-0,4$ & $-0,4$ & 0,9 & 0,5 & $-0,4$ & 0,1 & 0,9 & 0,8 & $-0,6$ & 0,8 & 0,7 & 0,6 & 1,0 & & & \\
\hline$S$ & $-0,5$ & 0,3 & 0,3 & 0,7 & 0,6 & $-0,1$ & $-0,1$ & $-0,1$ & 0,5 & $-0,2$ & $-0,2$ & 0,5 & $-0,4$ & $-0,4$ & $-0,5$ & $-0,1$ & 1,0 & & \\
\hline B & $-0,7$ & 0,5 & 0,5 & 0,5 & 0,6 & $-0,6$ & $-0,3$ & $-0,1$ & 0,3 & $-0,7$ & $-0,7$ & 0,7 & $-0,7$ & $-0,5$ & $-0,5$ & $-0,6$ & 0,6 & 1,0 & \\
\hline $\mathrm{Fe}$ & 0,2 & 0,4 & 0,4 & $-0,4$ & $-0,3$ & $-0,3$ & $-0,3$ & $-0,1$ & $-0,3$ & $-0,2$ & $-0,2$ & $-0,3$ & 0,1 & $-0,2$ & 0,3 & $-0,3$ & $-0,4$ & 0,1 & 1,0 \\
\hline
\end{tabular}

\section{CONCLUSÕES}

Propriedades químicas do solo são alteradas de acordo com o uso e manejo destinado aos solos do meio urbano. Nas margens da Sanga Lagoão do Ouro há três ambientes (padrões) distintos de acordo com a interferência antrópica dos diferentes locais.

Esses padrões são comandados por atributos da fertilidade do solo (1), pela acidez (2), e pela quantidade de $\mathrm{MO}, \mathrm{N}$ e K (3). Com essas informações é possível dizer a poluição gerada pelas atividades urbanas no perímetro da Área de Preservação Ambiental causa degradação ao solo que pode refletir na qualidade da água da Sanga e interferir na saúde das pessoas e animais que fazem uso da mesma. 


\section{AGRADECIMENTOS}

Ao CNPq pela concessão de bolsa de Iniciação Científica a primeira autora e a FAPERGS pelo auxílio financeiro para a realização da pesquisa.

\section{REFERÊNCIAS BIBLIOGRÁFICAS}

ACCIOLY, A.M.A.; SIQUEIRA, J.O. Contaminação química e biorremediação do solo. In: NOVAIS, R.F.; ALVARES, V.H.; SCHAEFER, C.E.G.R. Tópicos em ciência do solo, Viçosa : SBCS, 2000. V. 1, p.299-352.

BISSANI, C.A.; MEURER, E.J.; BOHNEN, H. Solos ácidos e solos afetados por sais. In: MEURER, E.J. (Org). Fundamentos de Química do Solo. Porto Alegre: Genesis, 2006. 2 ed, p. $181-205$.

BRASIL. Lei Federal n. 6.939 de 31 de agosto de 1981. Define a política nacional do meio ambiente.

BREJDA, J. J.; KARLEN, D. L.; SMITH, J. L.; ALLAN, D. L. Identification of Regional Soil Quality Factors and Indicators: II. Northern Mississippi Loess Hills and Palouse Prairie.Soil Science Society American Journal, Madison, v.64, n.6, p.2125-2135, nov./dez. 2000.

CHRISTOFOLETTI, A. Geomorfologia. São Paulo: Blücher, 1979.188p.

CQFS - Comissão de química e fertilidade do solo - RS/SC. Manual de adubação e calagem para os Estados do Rio Grande do Sul e de Santa Catarina. Porto Alegre: SBCS - Núcleo Regional Sul/UFRGS, 10ed., 2004, 400p.

FONTOURA, R.H.R. Diagnóstico e prognóstico da Vila Tonetto - Camobi. Santa Maria, RS: Universidade Federal de Santa Maria, 1993. 50p. Monografia de bacharelado em Geografia, Universidade Federal de Santa Maria, 1993

GLASSON, E. ; DALMOLIN, R. Caracterização e planejamento de uso de solos urbanos. Revista opinião, v. 30, n. 3, set./dez. 2005.

JACQUES, A.V.A. A queima das pastagens naturais - efeitos sobre o solo e a vegetação. Ciência

Rural, Santa Maria, v. 33, n. 1, p.171-181, jan./fev. 2003.http://www.scielo.br/pdf/cr/v33n1/14164.pdf

LAURENT, M.; ROBIN, O. P.; PIERRE, T. J. Multivariate statistical analysis of trace elements in soil on Spoil Heap, South East Congo-Brazzaville. African Journal of Basic \& Applied Sciences, Dubai, v.2, n.3-4, p.81-88, mai./ago. 2010. 
MACHADO, L.O. Adubação fosfatada. Informativo. Disponível em: http://www.dpv24.iciag.ufu.br. Acessado em 07 agosto 2012.

MADRID, L.; DÍAZ-BARRIENTOS, E.; MADRID, F. Distributions of heavy metals contents of urban soils in parksof Seville.Chemosphere, v.49, p.1301-1308, 2002.

MEnEgAT, R. (Coord.) Atlas ambiental de Porto Alegre. Porto Alegre: Ed.Universidade/UFRGS, 1998. p.39-40.

MORENO, J.A. Clima do Rio Grande do Sul. Porto Alegre: Secretaria da Agricultura, 1961. 73 p.

PEDRON, F. de A.; DALMOLIN, D. S. R. Caracterização e Manejo de Solos Urbanos. Centro de Ciências Rurais, Santa Maria, 2002.

PEDRON, F. de A. Classificação do potencial de uso das terras no perímetro urbano de Santa Maria - RS. Santa Maria, RS: Universidade Federal de Santa Maria, 2005. 74p. Dissertação de mestrado em Ciência do Solo, Universidade Federal de Santa Maria, 2005.

PEDRON, F. de A.; DALMOLIN, R. S. D.; AZEVEDO, A. C.; KAMISNKI, J. Solos Urbanos. Ciência Rural, Santa Maria, v.34, n.5, out. 2004.http://www.scielo.br/pdf/cr/v36n2/a17v36n2.pdf

SOUZA, D. M. G. de; MIRANDA, L. N. de; OLIVEIRA, S.A. de. Acidez do solo e sua correção.

In.:NOVAIS, R. F.; ALVAREZ, V.; BARROS, N. F.; FONTES, R. L. F.; CANTARUTTI, R. B.; NEVES, J. C.

L.Fertilidade do Solo. Viçosa: SBCS, 2007. p.205-274.

STRECK, E. V.; KÄMPF, N.; DALMOLIN, R. S. D.; KLAMT, E.; NASCIMENTO, P. C.; SCHNEIDER, P.Solos do Rio Grande do Sul. Porto Alegre: UFRGS. 2002. 107 p.

TEDESCO, M. J.; GIANELLO, C.; BISSANI, C. A.; BOHNEN, H.; VOLKWEISS, S. J. Análise de solo, plantas e outros materiais. Porto Alegre: Departamento de Solos, UFRGS, 1995. 2 ed. 174 p.

VELOSO, C. A. C.; BORGES, A. L.; MUNIZ, A. S.; VEIGAS, I. A. de J. M. Efeito de diferentes materiais no $\mathrm{pH}$ do solo. Scientia agrícola, Piracicaba, v.49, n.1, p.123-128, jan./dez.1992.http://www.scielo.br/pdf/sa/v49nspe/15.pdf 